\title{
Laser-fabricated castor oil-capped silver nanoparticles
}

This article was published in the following Dove Press journal:

International Journal of Nanomedicine

22 March 201 I

Number of times this article has been viewed

\author{
Reza Zamiri' \\ Azmi Zakaria' \\ Hossein Abbastabar ${ }^{2}$ \\ Majid Darroudi ${ }^{3}$ \\ Mohd Shahril Husin' \\ Mohd Adzir Mahdi ${ }^{4}$ \\ 'Department of Physics, Faculty \\ of Science, ${ }^{2}$ Department of Chemistry, \\ Faculty of Science, ${ }^{3}$ Advanced \\ Materials and Nanotechnology \\ Laboratory, Institute of Advanced \\ Technology (ITMA), ${ }^{4}$ Wireless and \\ Photonics Networks Research \\ Center, Faculty of Engineering, \\ Universiti Putra Malaysia, \\ Serdang, Selangor, Malaysia
}

Correspondence: Azmi Zakaria

Department of Physics, Faculty of Science, Universiti Putra Malaysia, 43400 UPM Serdang, Selangor, Malaysia Tel +60176018195 Fax +60389454454 Email azmizak@science.upm.edu.my

\begin{abstract}
Silver nanoparticles were fabricated by ablation of a pure silver plate immersed in castor oil. A Nd:YAG-pulsed Q-switch laser with 1064-nm wavelength and 10-Hz frequency was used to ablate the plate for 10 minutes. The sample was characterized by ultraviolet-visible, atomic absorption, Fourier transform-infrared spectroscopies, and transmission electron microscopy. The results of the fabricated sample showed that the nanoparticles in castor oil were about 5-nm in diameter, well dispersed, and showed stability for a long period of time.
\end{abstract}

Keywords: laser ablation, silver nanoparticles, castor oil

\section{Introduction}

Currently, nanoparticles (NPs) are used in several scientific applications, but among these silver nanoparticles (Ag-NPs) are predominant. This is because of several characteristic features of this type of metal NP. ${ }^{1-3}$ Antimicrobials and nanocomposite fabrication are some of the highly useful applications, among others, of applications that were attributed to Ag-NP. ${ }^{4,5}$ In the fabrication of NPs, it is very important to control particle size, shape, and morphology. Laser ablation in liquid media is a simple and clean method for synthesis of NPs. ${ }^{6-9}$ In this technique, there is no need to use any chemical reagents (such as $\mathrm{NaBH}_{4}$ ) in the fabrication process or any purification techniques to characterize the produced NPs.

Agglomeration of particles is a big challenge in the synthesis of NPs. Much research work has been done to overcome this challenge. For example, NPs using fatty acids (oleic and lauric acid) and vegetable oils as stabilizers have been synthesized. ${ }^{10-12}$ It was found that these materials consist of amphiphilic molecules with polar carboxylic groups which are able to adsorb NPs, and their nonpolar long carbon chain prevents NPs agglomeration through steric repulsion.

Castor oil is a vegetable oil obtained by cold pressing the seeds and subsequent clarification of the oil by heat. It has high viscosity, high polarity, and very low vapor pressure and optical activity in comparison with other oils. Castor oil is classified as a safe and effective stimulant laxative by the US Food and Drug Administration (FDA). It is a triglyceride containing fatty acid chains, $90 \%$ of which are ricinoleic acid. Oleic and linoleic acids are the other significant components. ${ }^{12}$ With the above characteristics, it is expected that castor oil can be used as a good stabilizer in NPs fabrication. In this study, we report fabrication of Ag-NPs in castor oil. To the best of our knowledge, fabrication of Ag-NPs in castor oil using laser ablation has not been reported previously. 


\section{Experimental}

For the fabrication of Ag-NPs, a silver plate was ablated by laser in castor oil for $10 \mathrm{~min}$. As shown schematically in Figure 1, the plate with high purity $(>99.99 \%)$ was located $5 \mathrm{~mm}$ behind a glass cell wall filled with $10 \mathrm{~mL}$ of castor oil. A nanosecond-pulsed Q-Switched Nd:YAG laser (Brilliant; Lambda Photometrics Ltd, Hertfordshire, UK) with $10-\mathrm{Hz}$ repetition rate, 5-ns pulse duration, and $360 \mathrm{~mJ} /$ pulse energy at its original wavelength $(1064 \mathrm{~nm})$ was applied. A lens with focal length of $250 \mathrm{~mm}$ was used to focus the laser pulses onto the silver plate. During plate ablation, the solution was stirred magnetically to disperse the produced NPs. An atomic absorption spectrometer (AAS-S Series; Thermo Scientific, San Jose, CA) was used to measure concentration of Ag-NPs in castor oil. The obtained concentration of Ag-NPs in castor oil was $0.13 \mathrm{mg} / \mathrm{L}$. Due to the high viscosity of castor oil, it was diluted with ethanol for atomic absorption spectroscopy. The prepared sample was characterized using a UV-Vis double beam photospectrometer (Shimadzu, Columbia, SC), a transmission electron microscope (TEM, Hitachi H-7100; Hitachi, Tokyo, Japan), and a Fourier transforminfrared (FT-IR) spectrometer (1650; Perkin Elmer, Waltham, MA).

\section{Results and discussion}

Figure $2 \mathrm{~A}$ indicates the absorption spectrum of the castor oil immediately after laser ablation of the silver plate inside it. The appearance of the maximum absorption peak around $400 \mathrm{~nm}$ confirms that the solution contained AgNPs, and that this peak originated from the oscillation of collection of free conduction electrons of Ag-NPs, which is called surface plasmon resonance. The ultraviolet-visible spectrum of the Ag-NPs in castor oil was measured after a period of 2 months in order to check the ability of castor oil as a stabilizer. As shown in Figure 2B, the spectrum does not show any significant change in comparison with the

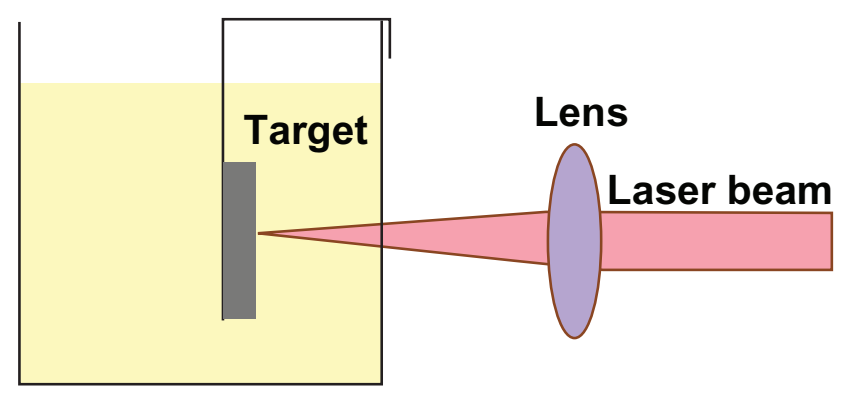

Figure I The laser ablation experimental set-up.

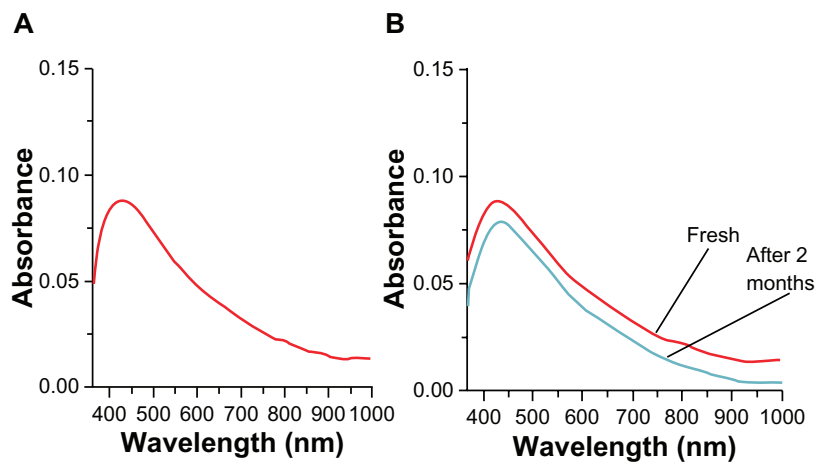

Figure 2 Ultraviolet-visible spectra of A) sample for freshly prepared silver nanoparticles (Ag-NPs) in castor oil and B) samples for freshly prepared and for 2 month lapse of $\mathrm{Ag}-\mathrm{NPs}$ in castor oil.

spectrum of the freshly prepared sample; however, there is a small reduction in absorption. This showed that the Ag-NPs produced in castor oil using the laser ablation technique were stable and did not agglomerate during storage of the sample at room temperature for quite a long period of time. The slight decrease in absorption intensity was possibly due to the sedimentation of larger particles.

Figure 3 indicates the TEM images and the corresponding size distributions of prepared NPs. The images show wellscattered and nonclustered NPs with a spherical shape. The spherical shape NPs can be very appropriately used for drug loading and for most biological applications such as antibacterial properties. ${ }^{13}$ Figure 3 shows an approximate 5.06 $\mathrm{nm}$ average diameter for freshly prepared $\mathrm{Ag}-\mathrm{NPs}$ obtained from two areas.

Figure 4 shows the mechanism of capping Ag-NPs with castor oil. NPs are formed via nucleation, transition, and crystal growth of materials such as silver atoms, clusters, and droplets that were emitted from the silver plate upon laser ablation. ${ }^{14}$ Castor oil can adsorb the produced Ag-NPs and long-chain hydrophobic moieties protect them through a steric stabilization mechanism. This steric hindrance can overcome the tendency of AgNPs to agglomerate.

FT-IR spectroscopy of castor oil and castor oil containing Ag-NPs (Figure 5) shows absorption bands at 3448, 2923, 2857,1739 , and $1160 \mathrm{~cm}^{-1}$ related to the vibrational-stretching mode of $\mathrm{O}-\mathrm{H}$ (intermolecular hydrogen bond), $\mathrm{C}-\mathrm{H}\left(\mathrm{sp}^{2}\right)$, $\mathrm{C}-\mathrm{H}\left(\mathrm{sp}^{3}\right), \mathrm{C}=\mathrm{O}$, and $\mathrm{C}-\mathrm{O}$, respectively. In addition, the appearance of the absorption band at $3780 \mathrm{~cm}^{-1}$ can be attributed to nonhydrogen-bonded $\mathrm{O}-\mathrm{H}$ stretching vibration. We believe that the existence of Ag-NPs prevents intermolecular hydrogen bonding, and therefore, the vibrational stretching modes of free $\mathrm{O}-\mathrm{H}$ appear at a higher wave number. ${ }^{15}$ 

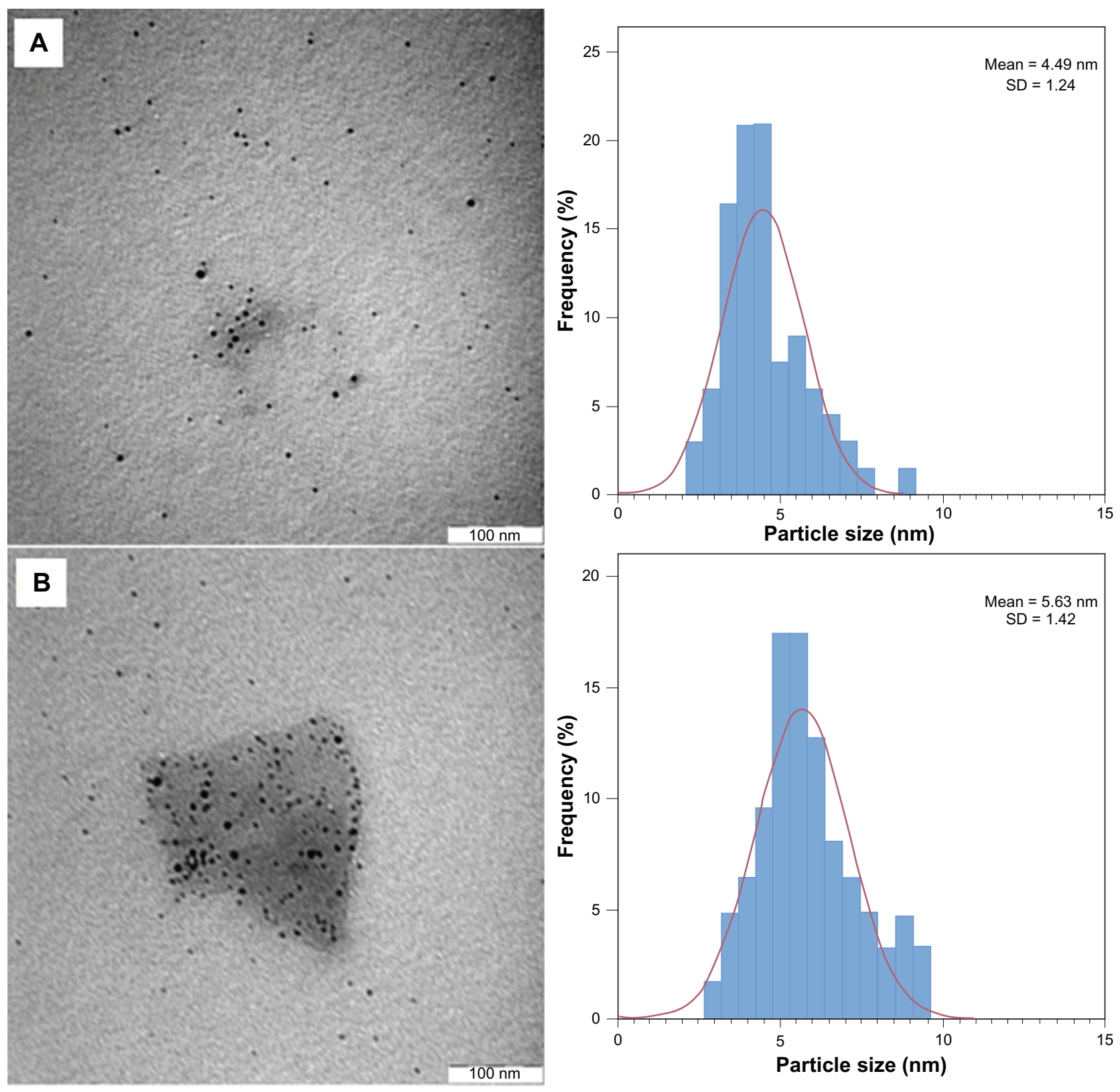

Figure 3 Transmission electron micrographs of castor oil containing silver nanoparticles. Abbreviations: SD, standard deviation.

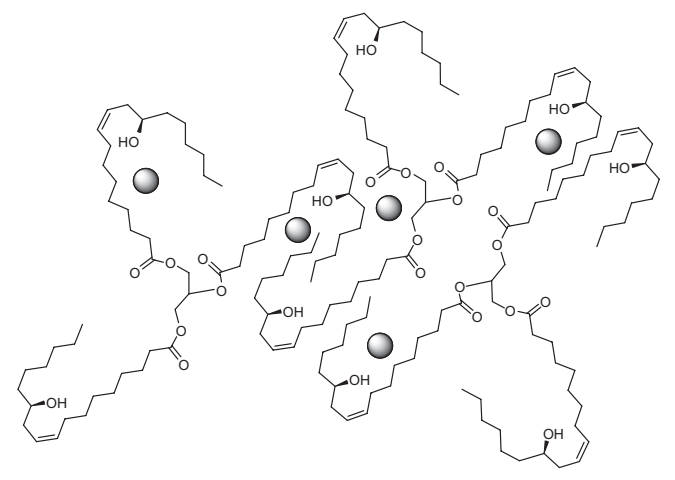

Figure 4 Schematic steric stabilization of silver nanoparticles in castor oil.

\section{Conclusion}

Ag-NPs have been successfully prepared in castor oil by laser ablation from a silver plate. The results obtained showed that the produced Ag-NPs were well dispersed and also stable for quite a long period of time. This ability of castor oil to prevent agglomeration of Ag-NPs is due to the presence of long-chain hydrophobic moieties.

\section{Acknowledgment}

The authors are grateful to the Ministry of Higher Education of Malaysia for supporting this work under Research University Grant Scheme No. 05-01-09-0754RU. 


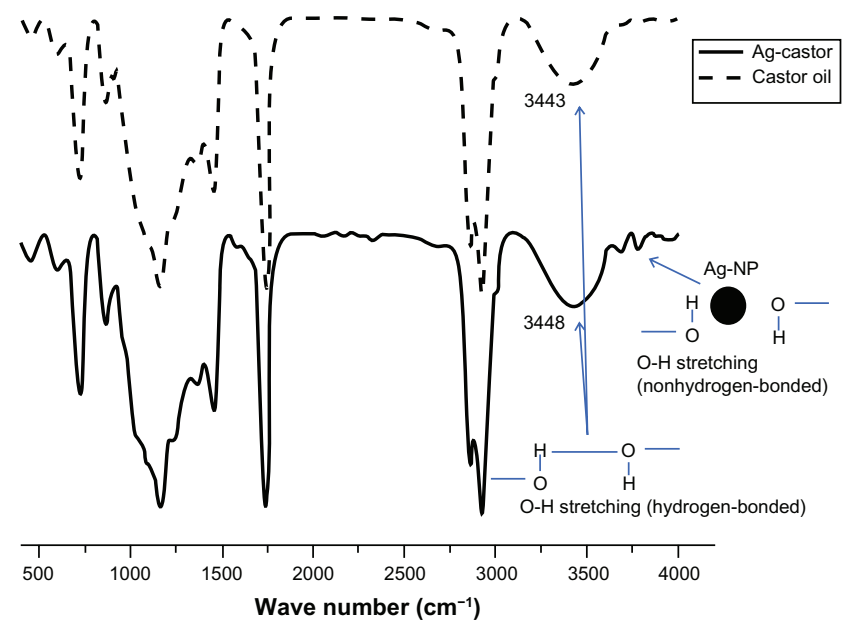

Figure 5 Fourier transform-infrared spectra of castor oil only and castor oil containing silver nanoparticles (Ag-NPs).

\section{Disclosure}

The authors report no conflicts of interest in this work.

\section{References}

1. Carter SA, Scott JC, Brock PJ. Enhanced luminance in polymer composite light emitting diodes. Appl Phys Lett. 1997;71(9): 1145-1147.

2. Yu G, Gao J, Hummelen JC, Wudl F, Heeger AJ. Polymer photovoltaic cells: enhanced efficiencies via a network of internal donor-acceptor heterojunctions. Science. 1995;270(5243):1789-1791.

3. Elghanian R, Storhoff JJ, Mucic RC, Letsinger RL, Mirkin CA. Selective colorimetric detection of polynucleotides based on the distancedependent optical properties of gold nanoparticles. Science. 1997; 277(5329):1078-1081.
4. Dowling DP, Betts AJ, Pope C, McConnell ML, Eloy R, Arnaud MN. Anti-bacterial silver coatings exhibiting enhanced activity through the addition of platinum. Surf Coat Technol. 2003;163-164(30): 637-640.

5. Song C, Wang D, Lin Y, Hu Z, Gu G, Fu X. Formation of silver nanoshells on latex spheres. Nanotechnology. 2004;15(8): 962-965.

6. Kokkoris M, Trapalis CC, Kossionides S, et al. RBS and HIRBS studies of nanostructured $\mathrm{AgSiO}_{2}$ sol-gel thin coatings. Nucl Instrum Methods Phys Res B. 2005;188:67-72.

7. Zamiri R, Azmi BZ, Darroudi M, et al. Preparation of starch stabilized silver nanoparticles with spatial self-phase modulation properties by laser ablation technique. Appl Phys A Mater Sci Process. 2010;102(1): 189-194.

8. Zamiri R, Zakaria A, Abbastabar Ahangar H, Sadrolhosseini AR, Mahdi MA. Fabrication of silver nanoparticles dispersed in palm oil using laser ablation. Int J Mol Sci. 2010;11(11):4764-4770.

9. Zamiri R, Azmi BZ, Sadrolhosseini AR, Zaidan AW, Mahdi MA. Preparation of silver nanoparticles in virgin coconut oil using laser ablation. Int J Nanomed. 2010;6:71-75.

10. Wu N, Fu L, Su M, Aslam M, Wong KC, Dravid VW. Interaction of fatty acid monolayers with cobalt nanoparticles. Nano Lett. 2004;4(2): 383-386.

11. Song HT, Choi JS, Huh YM, et al. Surface modulation of magnetic nanocrystals in the development of highly efficient magnetic resonance probes for intracellular labeling. J Am Chem Soc. 2005;127(28): 9992-9993.

12. Da Silva EC, da Silva MGA, Meneghetti SMP, et al. Synthesis of colloids based on gold nanoparticles dispersed in castor oil. J Nanopart Res. 2008;10 Suppl 1:201-208.

13. Khanna PK, Nair CKK. Synthesis of silver nanoparticles using cod liver oil (fish oil): green approach to nanotechnology. Int $J$ Green Nanotechnol. 2009;1(1):3-9.

14. Yang GW. Laser ablation in liquids: applications in the synthesis of nanocrystals. Prog Mater Sci. 2007;52(4):648-698.

15. Pavia LD, Lampman GM, Kriz SG. Introduction to Spectroscopy. Philadelphia, PA: Cengage; 2009:47-50.
International Journal of Nanomedicine

\section{Publish your work in this journal}

The International Journal of Nanomedicine is an international, peerreviewed journal focusing on the application of nanotechnology in diagnostics, therapeutics, and drug delivery systems throughout the biomedical field. This journal is indexed on PubMed Central, MedLine, CAS, SciSearch ${ }^{\circledR}$, Current Contents ${ }^{\circledR} /$ Clinical Medicine,

\section{Dovepress}

Journal Citation Reports/Science Edition, EMBase, Scopus and the Elsevier Bibliographic databases. The manuscript management system is completely online and includes a very quick and fair peer-review system, which is all easy to use. Visit http://www.dovepress.com/ testimonials.php to read real quotes from published authors. 